ORIGINAL ARTICLE

\title{
Investigation of the Mediator Role of Cultural Variables in Sports Club Management for Undergraduate Sports Management Curriculum Programs
}

\author{
SERDAR SAMUR ${ }^{1}$ \\ ${ }^{1}$ Istanbul Gedik Üniversity, Sports Science Faculty,Istanbul Turkey, Email:ssamur_2002@yahoo.com, Cell: +905076047320, Adress : \\ Çamlık Mahallesi, Nazende Sok, No : 2 Kurtköy,Istanbul, Turkey
}

\begin{abstract}
Change management in sports organizations is important in terms of organizational continuity. Sports Clubs, like other organizations, have their own behavioral patterns, beliefs and values. The sum of these differences constitute the variables within the organizational culture. Sports clubs that are aware of and develop their own cultural variables have a healthy organizational continuity. The aim of this study is to define the cultural variables of a sports club and to examine these variables in sports management education. This research was carried out according to qualitative research methods.According to the findings obtained in the research, it was concluded that Institutional purposes, principles, understanding and rules, norms, beliefs and symbols and basic values are important among the culture variables.
\end{abstract}

Keywords : Sports Club, Culturel Variable,Cirriculum,Mangement,Sustainability

\section{INTRODUCTION}

It is getting harder and harder to get a share from the economic size of the Sports Industry in the conditions of increasing competition. The change in technology is rapidly changing the ways of doing business and cultural structures of institutions. Sports clubs that see this change as a necessity and can define the issues of change are trying to adapt themselves to the change.

The most important step of change in organizations is to know the cultural codes of the organization and to adapt it to the current time. Revealing these cultural codes, which are conceptually dominant and not very easy to define, and raising awareness in this direction are among the priority topics of Sports Management curriculum.

The most appropriate tool that sports organizations can use to transfer the developments in their external environment to their internal structure should be to define the organizational culture.

According to Schein (1993) "the model of basic assumptions that the organization discovers during its adaptation to the external environment and internal integration, and accepts as valid because it gives good results, and therefore should be taught to new members as the most accurate way to understand, think and feel them" organizational culture. is called.

Organization culture; It is the sum of the attitudes, behaviors, values and norms that are accepted by the members of the organization and that guide the organization by regulating organizational life (Bakan, 2008).

Organizational culture is "the system of norms, behaviors, values, beliefs and habits that direct the behavior of people in an organization" (Dinçer, 1992:271). Culture gives people feeling and intuition about what they have to do and how they should behave. In other words, organizational culture is the dominant values and beliefs that shape the thoughts and behaviors of the members of the organization.

Corporate culture shows the effect of the common values that employees believe and share in a wide area such as the way the work is carried out in the organization, the relations between the employees, solidarity and performance development.

Culture emerges as a reflection of the founding philosophy of the organization, and then the role of managers and leaders, the values and beliefs of the employees, and the unique dynamics of the sector in which they work, become unique to that institution (Akıncı and Sohodol, 2004).

Corporate culture defines common and accepted behaviors and relations in the institution, facilitates finding appropriate solutions where there are no rules and issues that will motivate individuals, and guides the organization in the management of information within the institution, the transfer of values and the regulation of internal relations.

Culture provides an average framework. It enables to interpret and think about the events and phenomena encountered within this framework. Thus, it also constitutes the basic point of social integration and/or separation.

Corporate culture takes into account the mental structures that shape an organization, the interpersonal interactions and the link between concrete symbols, and focuses on the current state of affairs in the organization rather than the temporary attitudes of people.

Organizational culture has an extremely important effect on the invisible organizational performance as it allows the definition of many different variables. (Lee and Yu, 2004).

The following is the result of the authors' consensus to define organizational culture with different variables:

- $\quad$ Corporate Vision, Mission and Aims

- $\quad$ Corporate principles

- $\quad$ Corporate Understanding and Rules

- Cultural norms of the organization

- Communication

- The values and beliefs and symbols of the organization

- $\quad$ Core and shared values

- Corporate purposes:

Purpose refers to the state that a business intends to achieve in the future. Objectives form the basis for the organization of business resources to realize the situation 
achieved in the future, that is, the formation of strategy, and they are a tool in the realization of strategy and mission objectives (Eren, 2003).

The objectives of the business are what it wants to achieve as a result of its activities. They are the results that indicate what the business does, why it does the activities, what it does or what it does to achieve. (Ülgen and Mirze, 2007, 185).

The vision is the expression of the situation that they want their businesses to be in the future. It is an expression of a situation or situation that is desired to be reached or to be in the future (Ülgen, 2007). The visions of businesses express where they want to be about the future.

The missions of the enterprises are the values that direct the enterprise, determine the long-term goals and distinguish the enterprises from their competitors. It is the mission that makes the business special. Mission is related to the existence and spirit of the enterprise (Ülgen and Mirze, 2007).

While the mission determines the reason for existence of a company, the objectives are the basic steps that make up the vision. Goals, on the other hand, are sharper and more measurable, and they are generally quantitatively stated (Ülgen and Mirze, 2007).

Corporate principles: Corporate governance focuses on four fundamental principles: Fairness, Transparency, Accountability and Responsibility. (Corporate Governance Association of Turkey)

- The principle of fairness is the expression of the company's management to treat all beneficiaries equally. This principle refers to the protection of shareholder rights and the implementation of the agreements made.

- $\quad$ The principle of transparency requires the company to share accurate, open and comparable information with the public.

- The principle of accountability requires the board of directors to monitor the performance of the top management independently and to ensure the accountability of top managers to the shareholders.

The principle of responsibility means that companies operate in a way that complies with laws and regulations that reflect social values while creating value for their shareholders. (Corporate Governance Association of Turkey)

It is necessary to determine the vision and mission of the organizations and the general and specific goals of the organization, and all principles and rules regarding work and operation should be put forward in writing (Yazıcıoğlu and Koç, 2009).

Institutional understanding and rules: Each institution has its own unique social structure, the behaviors, value judgments, belief systems and relationship patterns desired by this structure.

The phenomenon of "collective behavior" as a behavior plane that enables people to prepare for more specific behaviors that regulate their behavior in general reveals the institutional behavior plane.

The level of institutional behavior is the behaviors that are in accordance with the institutional behavior standards, formed according to the institutional role and status, accepted by the institutional will and appropriate to the field of institutional

tolerance.

(https://sociological.wordpress.com)

Norms: Norms are the way members respond to critical events (Akbaba, 2002). In other words, norms are rules of behavior and criteria developed by the organization in accordance with the cultural values of the organization and adopted by the majority of employees. A norm cannot be legitimate unless it is rooted in cultural values. Norms show how employees will behave in the organization, how they will relate and how they will communicate with others (Başaran, 1982). For example, colleague support, taking the opinions of colleagues, solving special disciplinary problems, and avoiding unnecessary discussions with managers (Çelik, 2000).

Cultural norms and beliefs support or hinder creativity and innovation, depending on the level of influence of individuals and groups (Martins \& Terblanche, 2003).

Value Judgments and Shared Values: Value Judgment: It is the acceptance of values as they are without any discussion of their correctness. Employees have strong value judgments about people, objects and events. For example, business should be based on profit, school should educate, etc. (Steel, 2000; İpek, 1999).

Values: Values are the source of criteria for characterizing, evaluating and judging the behavior of employees (Çelik, 2000).

Values represent ideal desired goals. These goals are generally abstract behavior patterns that are desired to be acquired such as honesty, dignity and success (Sabuncuoğlu \& Tüz, 2001).

The source of the cultural values of the organization are the traditions of the society in which the organization is located, and the beliefs developed by the religious and functional systems. The organization appropriates these values, which it brings from the culture of the society through its employees, by processing, assimilating and developing within itself (Başaran, 1982). As examples of values, we can show openness, trust, cooperation and close friendship (Çelik, 2000).

Shared Values are open to everyone in the organization and permeate every activity the organization undertakes. Values are often not written (Pawlas, 1997)

Values are the answer to the "how" question in the corporate idea spectrum. Values such as "integrity of principles", "honesty", "openness", "equal opportunity" and "progress" serve as a compass that the institution uses not to lose its way while continuing its activities (Erengül 2007: 79).

Rokeach (1973) defines the concept of value as a persistent belief that a particular behavior and purpose of existence is personally and socially preferable to its opposites.

All members of the group may not have the same values, but the majority of the active members should agree on them and the members of the group should support the determined values of the group (Ingelsson et al. 2012: 2).

Values are the answer to the "how" question in the corporate idea spectrum. Values such as "integrity of principles", "honesty", "openness", "equal opportunity" and "progress" serve as a compass that the institution uses not 
to lose its way while continuing its activities (Erengül, 2007).

According to Hofstede, the lowest layer and essence of culture are values. The core ethos is often made up of the founder's beliefs, reinforced by experience, and nurtured by key groups in the organization. These values need to be embedded in order to help achieve organizational goals. Accordingly, the values (Kitchen and Schultz, 2001) :

- It should be an indication of the strategic purpose,

- It should be shared widely in terms of willingness,

- Must focus on winning

- It must be consistent with its purpose.

Network: Every organization and culture asks, "What is really going on in the organization?" It has a communication system to disseminate relevant information. In some ways the system is informal. Here, every manager needs to know the ways necessary to disseminate information quickly within the system.

The effective establishment of the communication system facilitates the interaction of both managers and professional employees with each other in line with the determined targets (Yazıcıoğlu and Koç, 2009).

Topics describing beliefs, behaviors and symbols: Beliefs, which are indispensable elements of human psychology, are a continuous network of emotions formed by perceptions and definitions of an aspect of their own world. Beliefs are not interpreted as positive or negative in individual behaviors. In other words, they are neutral (Eren,1984), but a consistent unity is required in beliefs and ideas. The meaning of this unity is not that each individual necessarily shares the same opinion or that those who differ in opinion are put under pressure, but that different opinions can be discussed in a comfortable and peaceful environment, and that they can be brought to a conclusion smoothly. (Bülbül,1993)

Edward Sapir defined culture as the unity of practices and beliefs, material and spiritual elements that we learn through a social process that determines the structure (relationships) of our existence.

Observable forms of organizational culture are symbols and slogans. Symbols are used by organizations to convey organizational culture.

Leslie White thought of culture as a set of symbols and defined culture as an organization of material elements, behaviors, thoughts and emotions based on symbols consisting of symbols. Symbols are used to express both observable and unobservable elements of culture.

Belkıs Temren defined the symbol as concrete things or signs that make things that cannot be perceived with emotions perceptible. Therefore, the symbol arises from the comparison of a certain objective event or phenomenon with a concept of intellectual origin or the expansions and connotations of its own concept.

The cultural symbols system undertakes the task of integrating, integrating and, most importantly, raising new members of the community and provides differentiation.

\section{MATERIALS AND METHODS}

Limitations: This research is limited to 5 professional clubs in Turkey.
Participants : 5 people who are senior and middle level managers in the sports club participated in this study.

Method : The research was conducted with a qualitative method. In qualitative research, qualitative data collection methods such as observation, interview and document analysis are tried to present perceptions and events in a realistic and holistic way in the natural environment (Yıldırım \& Şimşek, 2005).

Development of Data Collection Tool: Data were collected through interview techniques.

Interview technique and questions: As the interview technique, Patton's interview form approach was used and a single open-ended question was asked, and if a sufficient answer could not be obtained from the question, a subquestion was added.

The main question in the interview form is as follows :

Question -1 : What do you think about the issues that affect the development of your corporate culture and the examples that describe them?

Sub-question: What are your subjects that make you different?

Data analysis : Content analysis was used in the data. The answers given by the participants were grouped and interpreted in terms of similarities.

\section{RESULTS}

Theme : 1: When the determination of the objectives and principles of the institution and the participation of the employees in the business processes are analyzed; The following topics have been achieved for Institutional Purposes:

Adhering to the slogan 'Our children are our future' in an organization that considers raising athletes as the most important occupation,

- To be a sports social enterprise that applies an economic model to ensure its sustainability,

- $\quad$ To be recognized in the world as an exemplary sports club that trains professional athletes by applying the equity model,

- To make children love sports, to contribute to their being sportsmen and to prepare the naturally talented ones among them for professionalism,

- To give social responsibility messages to the society with the discourse of good individuals, good citizens and good athletes,

- To implement a real professional athlete training program based on measurement and evaluation,

- $\quad$ Emphasizing that the main purpose of the club is to raise Professional athletes.

The following conclusions have been reached for the Corporate Principles:

- $\quad$ Giving importance to institutionalization,

- To use the process approach within the system approach in management and to attach importance to continuous improvement,

- Giving importance to gender equality,

- $\quad$ Contributing to women's taking more roles as athletes and fans in sports,

- To use a fact-based scientific approach in decision making,

- Considering the needs and expectations of the fans, who are the most important stakeholders, 
- Developing good relations with the sports press,

- To achieve sustainable sportive success with controlled growth,

The following subjects have been determined as institutional competency criteria:

- To have up-to-date information,

- Activating values,

- Ability to use technology,

- Acting according to Personality Traits, Values and Attitudes,

- Being in Observable Behaviors,

- Reaching Superior Performance,

The following topics have been identified for Distinctive Competition:

In technical skill proficiency, running and playing at high tempo in every match:

- Developed self-discipline,

- Belief in Success - High Mental Stamina,

- Honest, Determined, Brave, Altruistic, Self-confident,

- Warrior Spirit, Fighting strength and stubbornness ability,

- Having high standard athletes,

The following topics have been determined as Understanding and Rules :

- To work for the development and updating of Human Resources in order to realize the goals and strategies in all units, depending on the objectives of the organization and common values,

- $\quad$ To prepare the administrative and technical staff with potential for the future,

- To pre-determine, monitor, support with necessary training and development programs,

- To strive for the provision and development of human resources potential from internal resources,

- $\quad$ Determining position competencies and ensuring that employees reach these competencies with their development plans,

- Determining the levels of the positions and determining the wage policies to be applied accordingly,

- To measure performance by creating objective and understandable evaluation systems,

- To implement the methods of material and moral appreciation and recognition for motivation,

- $\quad$ To make the stadium, halls and facilities more family friendly,

- $\quad$ Focusing on people and giving importance to their participation in all kinds of decisions,

- Defining the story of the brand,

- To act with team spirit in each unit,

- To ensure that the corporate culture is consistent

Theme -2 : When the features that will contribute to the harmony of common working conditions and internal peace are analyzed ;

The following topics related to Core Values have been identified:

- Quality

- Relevance

- Reliability

- Professional expertise

- Impartiality

- Transparency, Transparency
- $\quad$ Confidentiality in personal data

- Participation

- Accountability

- Accessibility

The following topics have been determined for the values specific to the institution:

- $\quad$ To create a management approach based on respect for people,

- $\quad$ To create a contemporary working environment that respects differences, considers equal opportunities, uses club resources efficiently, and values communication,

- Not to engage in a discourse, attitude or action contrary to gender inequality,

- To behave in a gentlemanly manner,

- Having a sense of teamwork,

- Giving importance to unifying elements,

- Believing in a fair competition environment,

- To be managed professionally,

- Foresight, determination and risk taking,

- Having the passion to achieve the most difficult,

- Working with trust, humility and honesty,

- Giving importance to learning, sharing and teaching,

The following topics have been identified for Shared Values:

- Sharing up-to-date information and applying it to business processes, which will facilitate the development towards a learning organization,

- $\quad$ Based on ethical values, quality service, trust and honesty in teamwork,

- To use continuous learning-development (TQM), process renewal, benchmarking and innovation management

Theme -3: When the unique behavioral patterns that make the institution different, their lifestyles, the use of historical codes to strengthen the sense of identity and belonging of the employees to the institution are analyzed;

The following topics have been identified regarding beliefs:

- we work together and develop together,

- we compete together, we will succeed together, we will reach the top together.

The following topics have been identified in terms of behavior:

- $\quad$ Staying away from grudge, hatred, violence and discriminating attitude,

- Those who want to live in a profanity-free status environment,

- Zero tolerance for all kinds of discrimination against women and girls,

- $\quad$ Contributing to increasing the presence of women and girls as role models and spokespersons,

- Expanding the slogan of no to gender-based chants,

- Developed self-discipline,

- Belief in success and high mental endurance,

- Honest, determined, brave, self-sacrificing, selfconfident,

- Warrior spirit-with the ability to fight and stubbornness,

The following topics have been identified as symbols:

- X Sports Club was founded on 26 December 1923 in İzmir. 
- Red color; From the blood of our martyrs and veterans, the unnamed heroes of the War of Independence,

- The dark blue color, on the other hand, is made of steel to represent durability and strength.

The following topics have been determined in terms of perspective on business life:

- Demonstrating participatory leadership in determining strategic direction,

- Taking calculated risks with steps and actions that will make a difference,

- Being assertive in the competition and achieving sporting success with a work effort that will end with a trophy,

- Enabling employees to participate in decision processes,
- Focusing on innovation and change rather than traditional values,

- Giving importance to institutional memory and stability, (Does what he writes, writes what he does)

- Having determined the working system, having people and arrangements that can measure and evaluate for objective evaluation,

- $\quad$ Based on strategic management,

- $\quad$ Trying to have an understanding that continues its work without compromising, regardless of the result, within the values of the club :

\section{DISCUSSION AND CONCLUSION}

Topics showing the themes and codes of the research are in Table-1.

Table -1: Themes and Codes

\begin{tabular}{|c|c|c|c|}
\hline 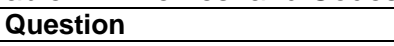 & Themes & Codes & Participants \\
\hline \multirow{3}{*}{$\begin{array}{l}\text { Can you give examples of } \\
\text { what are the issues that affect } \\
\text { the development of your } \\
\text { corporate culture and to } \\
\text { describe them? } \\
\text { Sub-question: What are your } \\
\text { subjects that make you } \\
\text { different? }\end{array}$} & $\begin{array}{l}\text { 1.Determining the Institutional } \\
\text { goals and principles in order to } \\
\text { achieve the Vision and Mission of } \\
\text { the Institution, and Employee } \\
\text { participation in business } \\
\text { processes }\end{array}$ & $\begin{array}{l}\text {-Corporate Purposes } \\
\text { - Principles } \\
\text {-Institutional Competence } \\
\text { - Norms } \\
\text { - Understanding and Rules } \\
\text { - Communication }\end{array}$ & $1,2,3,4,5$ \\
\hline & $\begin{array}{l}\text { 2.Features that will contribute to } \\
\text { compliance with common } \\
\text { working conditions and internal } \\
\text { peace }\end{array}$ & $\begin{array}{l}\text { Core Values and Shared Values } \\
\text { Unique to the Organization }\end{array}$ & $1,4,5$ \\
\hline & $\begin{array}{l}3 . \quad \text { Benefiting from } \\
\text { established,and historical codes } \\
\text { to strengthen the unique behavior } \\
\text { patterns, lifestyles, employees' } \\
\text { belonging to the institution and } \\
\text { their sense of identity that make } \\
\text { the institution different. }\end{array}$ & Beliefs, Behaviors, and Symbols & $1,2,3,5$ \\
\hline
\end{tabular}

Theme -1: When the issues related to the determination of the objectives and principles to achieve the Vision and Mission of the institution and the participation of the employees in the business processes are examined:

For Institutional Purposes, the following findings emerged:

Participants $(1,3)$ : They stated that a vision and mission are needed to achieve corporate goals and that it is the best way to describe the situation that a business intends to achieve in the future.

Participants $(2,5)$ : They explained that the Vision is necessary for corporate purposes and the definition of vision is an expression of the situation that institutions want to be in the future.

(Eren, 2003) claims that corporate goals are the basis for the organization of business resources to realize the situation achieved in the future, that is, the formation of strategy. Strategy and mission, on the other hand, express that they are in the position of a tool in the realization of their goals.

Participants $(1,5)$ : They explained that a company with a specific vision can achieve its goals more easily, and its missions are the values that guide the business, determine its long-term goals and distinguish the businesses from their competitors.
(Ülgen, 2007) claims that vision is a state of being or a state that is desired to be achieved or desired in the future. What makes the business special is the Mission.

Ülgen and Mirze (2007) argue that the mission is related to the existence and spirit of the business rather than the products the business produces, the customers it serves, or the pressure groups it is responsible for.

Ülgen and Mirze (2007) claim that while Mission determines the reason for existence of a company, objectives are the basic steps that make up the vision. Their goals are more precise and measurable, and they are usually the quantitative form of the goals.

The statements of the participants and the claims of the authors and the determination of the institutional goals were evaluated as a variable and it was seen that the statements of the participants and the claims of the authors supported each other.

The following findings were found for institutional principles :

Participants $(2,5)$ stated that there is a need for some principles and rules to be written about the way the work in the Institution is carried out. Within the framework of these rules, it is ensured that corporate goals are achieved in the light of vision and mission.

Yazıcıoğlu and Koç (2009) claim that within the framework of the Constitution of the Organization, the 
vision and mission of the organizations and the general and specific objectives of the organizations should be determined, and all principles and rules regarding work and operation should be put forward in writing.

Participants $(1,3,5)$ state that an institutional perspective is an important issue for sustainability today. Being able to take responsibility and accountability is a critical management practice. In the works performed, rights and benefits should be distributed by considering all stakeholders and there should be no doubt about the accuracy of any information coming out of the institution.

(Corporate Governance Association of Turkey) claims that corporate governance focuses on four basic principles such as Fairness, Transparency, Accountability and Responsibility.

The principle of fairness, the equal treatment of all rights holders by the company management,

The principle of transparency is the company's sharing of accurate, open and comparable information with the public,

The principle of accountability is to ensure the accountability of top managers to shareholders and

The principle of responsibility is that the institution operates in accordance with laws and regulations that reflect social values.

It has been seen that the statements of the participants and the claims of the corporate governance association support each other and it has been understood that the corporate principles will be considered as a different variable.

The following findings were found for institutional understanding and rules:

Participants $(3,4)$ stated that each institution has its own unique behaviors, shared value judgments, belief systems and communication styles, and an order of relations within the institution. There are some behavioral patterns that regulate behavior within the organization, they become organization specific.

(https://sociological.wordpress.com) claims that the institutional behavior plane is found. This plane defines behaviors that are in line with institutional behavior standards, formed according to institutional role and status, accepted by the institutional will, and appropriate to the field of institutional tolerance.

Participants $(3,5)$ stated that there are some norms developed by the organization in accordance with the cultural values of the organization. Norms, defined as codes of conduct, are rules and criteria of behavior adopted by the majority of employees. A norm is not valid unless it is based on cultural values.

Vulture (2002) claims that norms are defined as the way members respond to critical events.

Başaran (1982)claims that norms show how employees will behave in the organization, how they will relate and how they will communicate with others.

Martins and Terblanche (2003) Both cultural values, norms and beliefs support or hinder creativity and innovation, depending on the level of influence of individuals and groups.

The following results were obtained regarding the Communication Network :
Participants stated that, like other organizations, sports organizations also have a communication system to share information. Managers need to know and use the communication tools necessary to disseminate information quickly within business processes.

Yazıcıoğlu and Koç (2009) claim that the effective establishment of the communication system facilitates the interaction of both managers and professional employees with each other in line with the determined targets.

Theme -2: When the features that will contribute to the harmony of common working conditions and internal peace are analyzed;

The following issues were encountered regarding core values and Shared Values:

Participants $(4,5)$ state that Values are phenomena that are accepted as they are without discussing their accuracy. It is a phenomenon accepted by everyone that directly affects the way of doing business and defines a general belief.

Çelik (2000) \& İpek (1999) claim that employees have strong value judgments about people, objects and events. For example, business should be based on profit, school should educate, etc.

Participants $(1,5)$ state that values are a measure that directly affects the behavior of employees. Values represent ideal goals that are desired, not more.

Çelik (2000) claims that the values that form the core of organizational culture are the source of criteria for characterizing, evaluating and judging the behavior of employees.

Sabuncuoğlu and Tuz (2001) claim that values define goals to define ideal conditions and are generally considered as abstract behavior patterns that are desired to be acquired such as honesty, dignity and success.

Participants $(2,4)$ state that shared values highlight beliefs that define basic behavioral patterns and develop functional systems within the source of cultural values. We can cite openness, trust, cooperation and close friendship as examples of values.

Çelik (2000) \& Başaran (1982) claim that the organization appropriates these values, which it brings from the culture of the society through its employees, by processing, assimilating and developing within itself.

Participants $(1,5)$ state that the concept of value is considered as a permanent belief within a certain behavior and purpose of existence. Shared Values need to be open to everyone in the organization and have their traces in every activity of the organization.

Erengül (2007) claims that Values are usually not written. Values are the answer to the "how" question in the corporate idea spectrum. Values such as "integrity of principles","honesty","openness","equal

opportunity","progress" serve as a compass that the institution uses not to lose its way while continuing its activities.

According to Hofstede, the lowest layer and essence of culture are values. The core ethos is often made up of the founder's beliefs, reinforced by experience, and nurtured by key groups in the organization. These values need to be embedded in order to help achieve organizational goals. 
The idea that there are basic values and shared values in the culture variable of the organization is confirmed by the similarity between the statements of the participants and the claims of the authors.

Theme-3: When the unique behavior patterns that make the institution different, the lifestyles and the use of historical codes to strengthen the sense of identity and belonging of the employees to the institution are analyzed;

The following conclusions have been reached regarding beliefs, behaviors and symbols :

Participants $(1,3)$ state that beliefs are perceptions that individuals accept without hesitation in their own world. They act as guides in guiding one's behavior. There is a parallelism between a person's beliefs and ideas. Strong assumptions about the material and spiritual world are involved in shaping beliefs.

Eren (1984) claims that beliefs are not interpreted as positive or negative in individual behavior.

Bulbul (1993) claims that beliefs are neutral, but a consistent unity of beliefs and ideas is required. The meaning of this unity is not that each individual necessarily shares the same opinion or that those who differ in opinion are put under pressure, but that different opinions can be discussed in a comfortable and peaceful environment, and that they can be brought to a conclusion smoothly.

Edward Sapir defined culture as the unity of practices and beliefs, material and spiritual elements that we learn through a social process that determines the structure (relationships) of our existence.

Participants (2-5) stated that symbols are used by organizations to convey organizational culture. Symbols and slogans are used for both obvious and observable and unobservable aspects of organizational culture. While cultural symbols undertake the task of integrating within the institution, they also provide differentiation towards the environment.

Leslie White thought of culture as a set of symbols and defined culture as "an organization of material items, behaviors, thoughts and feelings, based on symbols (symbols)".

Belkıs Temren symbolizes the concept of "Concrete things or signs that make things that cannot be perceived with senses perceptible, are called symbols." defined as.

As a result of the closeness of the ideas of the participants and the claims and views of the authors, it has been seen that beliefs, behaviors and symbols are among the important variables in the corporate culture.

\section{REFERENCES}

1. Adler,J.N.(1980).Cultural Synergy: The Management of Cross Cultural Organizations, San Diego, Calif. University Associates.

2. Akıncı, V., B. and Sohodol, C.,(2004). Corporate Culture in Family Businesses: A Study on Advantages-Disadvantages and Suggestions.

3. Bakan, I. (2008), The Relationship Between Perceptions of "Organizational Culture" and "Leadership" Types and Demographic Characteristics of Managers: A Field Study", KMU FEAS Journal, Vol: 10, Issue: 14.

4. Basaran, I.E. (1982). Organizational Behavior. Ankara: Ankara University Faculty of Educational Sciences.
5. Bulbul, S.E (1993). The relationship between organizational climate and its functions and an Applied research in life insurance companies" (Published Master's Thesis) Istanbul University Institute of Social Sciences, Istanbul

6. Çelik, V. (2000). School Culture and Management (2nd Edition), Ankara: Pegem Publications.

7. Erengül B (2007) Culture Wizards, Evrim Publishing House, Istanbul.

8. Eren, E. (1984). Management Psychology, Istanbul University, Institute of Business Economics Publication, no: 66, Istanbul

9. Eren, E. (2005). Strategic Management and Business Policy. Istanbul: Beta Publications, 7th Edition, Publication No: 1203

10. Hoy, W. K. and Miskel, C. G. (1991). Educational Administration. McGraw Hill Inc.

11. Silk, C. (1999). Organizational Culture and Teacher-Student Relationship in Public and Private High Schools. Ankara: Ankara University Institute of Social Sciences, (Unpublished PhD Thesis).

12. Ingelsson P, Eriksson M and Lilja J (2012) Can Selecting The Right Values Help TQM İmplementation? A Case Study About Organisational Homogeneity At The Kurum Kültürü ve Değerlerine Yönelik Çalışan Farkındalığı...

13. Koçel, T. (2015). Family Business Congress Congress Book Istanbul, Turkey, Family Business and Entrepreneurship Application and Research Center, pp: 325-333.

14. Koçel, T., (2001). Business Management, Management and Organization, Behavior in Organizations, Classical-ModernContemporary and Current Approaches. Istanbul: Beta Publications.

15. Kitchen P J and Schultz D E (2001) Raising the Corporate Umbrella, Palgrave.

16. Lee, S. K. ve Kelvin Y. (2004). Corporate Culture and Organizational Performance. Journal of Managerial Psycholog, Volume : 19. Number : 4. (340-359).

17. Martins, E.C. ve Terblanche, F. (2003). Building Organizational Culture that Stimulates Creativity and Innovation. European Journal of Innovation Management, Volume: 6. Number: 1 (64-74).

18. Peterson,R,S.(1997).; A Directive Leadership Style İn Group Decision Making Can Be Both Virtue And Vice: Evidence From Elite And Experimental Groups. Journal of Personality and Social Psychology.

19. Pawlas, E.G. (1997). Vision and School Culture. NASSP Bulletin, Volume: 81. Number: 587. (118-128).

20. Sabuncuoğlu, Z. and Tuz, M. (2001). Organizational Psychology, Bursa: Ezgi Bookstore.

21. Schein, E. H. (2002). Organizational Culture. Trans.: Atilla Akbaba. Dokuz Eylul University Journal of Social Sciences Institute, Vol: 4, No: 3, (1-32).

22. Shahman, I. \& Tengilimoğlu, D. and Işık, O., (2008). A Field Study to Determine the Effect of Professionalization of Management on the Institutionalization Process in Private Hospitals, Journal of Gazi University Faculty of Economics and Administrative Sciences 10(2), pp:1-23

23. Sungur,S.(2007).Television Broadcasting and the Decline of Cultural Identities in the Clamp of Globalization, Istanbul University Social Sciences Institute PhD Thesis, Istanbul, $p$ 159 ,

24. Uçar, T. F., (2004). Visual Communication and Graphic Design. İnkılâp Publishing House, Istanbul, p.24,

25. Ülgen, H. and Mirze, S.K. (2007). Strategic Management in Business. Istanbul: Arıkan Press, Publication No: 206

26. Wagner, A. J. (1995). J. R. Hollenbeck; Management and Organizational Behavior, Newjersey Prentice Hall Inc.,

27. Yazıcıoglu, I. and Koç, H., (2009). A Comparative Research on the Determination of Institutionalization Levels of Family Businesses. Selcuk University Journal of Social Sciences Institute, 21, pp: 497-507. 